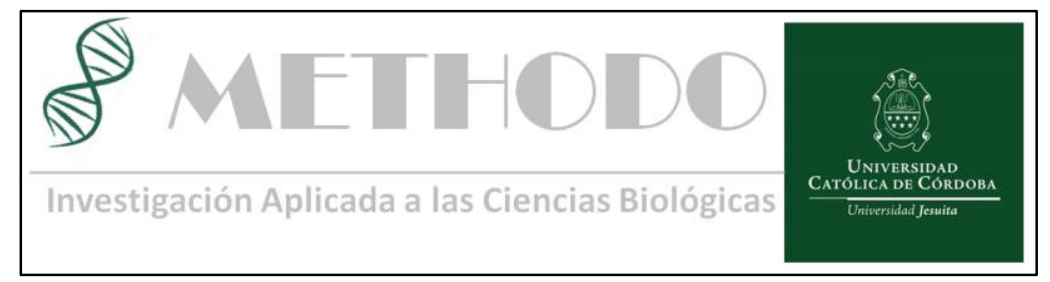

\title{
Úlceras orales a repetición y eritema nodoso: pensar en Enfermedad de Behçet
}

\section{Oral ulcers with repetition and erythema nodosum: thinking about Behçet's disease}

Ignacio Gutiérrez Magaldi ${ }^{1}$, Exequiel Bulacio ${ }^{1}$, Fernando Camporro ${ }^{1}$, María N. Bertorello ${ }^{1}$, Sofía Furrer ${ }^{1}$, Valentina Bressan ${ }^{1}$, Pablo Lucero ${ }^{1}$.

1Servicio Medicina Interna. Clínica Universitaria Reina Fabiola.

Correspondencia: Ignacio Gutiérrez Magaldi, Servicio de Medicina interna - Clínica Universitaria Reina Fabiola. Oncativo 1248 -X5004FHP- Córdoba, Argentina; e-mail: igutierrezmagaldi@gmail.com.

\section{Resumen}

La enfermedad de Behçet es una vasculitis sistémica crónica recurrente poco habitual en nuestro país. Se caracteriza por afectación mucocutánea, pero también, compromete otros órganos como ojo, sistema nervioso, gastrointestinal, musculoesquelético, cardiopulmonar y renal. Para el diagnóstico no se cuenta con un estudio específico, pero se se requiere cumplir con criterios propuestos por el Grupo Internacional de estudio de Enfermedad de Behçet 1990 y excluir patologías más frecuentes de presentación similar. El tratamiento se basa en antiinflamatorios no esteroideos, corticoides e inmunomoduladores.

\begin{abstract}
Behçcet's diseaseis a recurrent chronic systemic vasculitis uncommon in our country. It is characterized by mucocutaneous involvement, but also, it compromises other organs such as eye, nervous system, gastrointestinal, musculoskeletal, cardiopulmonary and renal. The diagnosis does not have a specific study, but it is necessary to comply with criteria proposed by the International Behçet Disease Study Group 1990 and to exclude more frequent pathologies of similar presentation. Treatment is based on non-steroidal antiinflammatory drugs, corticosteroids and immunomodulators.
\end{abstract}

\section{Introducción}

La enfermedad de Behçet es una vasculitis sistémica crónica recurrente, que puede afectar vasos de cualquier tamaño, tanto venas como arterias. (tabla 1).

Habitualmente tiene manifestaciones mucocutáneas, pero también, aunque en menor porcentaje, tiene afectación ocular, en sistema nervioso, gastrointestinal, musculoesquelético, cardiopulmonar y renal ${ }^{1}$.

Mujer de 47 años, médica laboral, hospitalizada por fiebre de cinco días de evolución a la cual se le agregó artritis de rodilla derecha y eritema nodoso en miembros inferiores. (Ver Figura $n^{\circ} 1$ y 2).

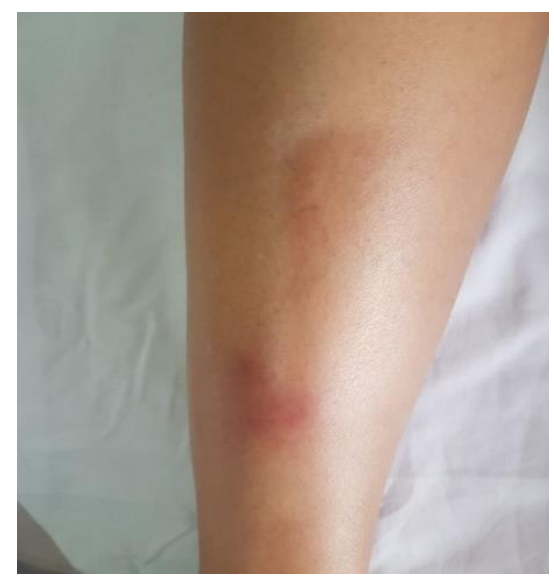

Figura $\mathbf{n}^{\mathbf{0}}$. Eritema nodoso en zona pretibial de MMII 


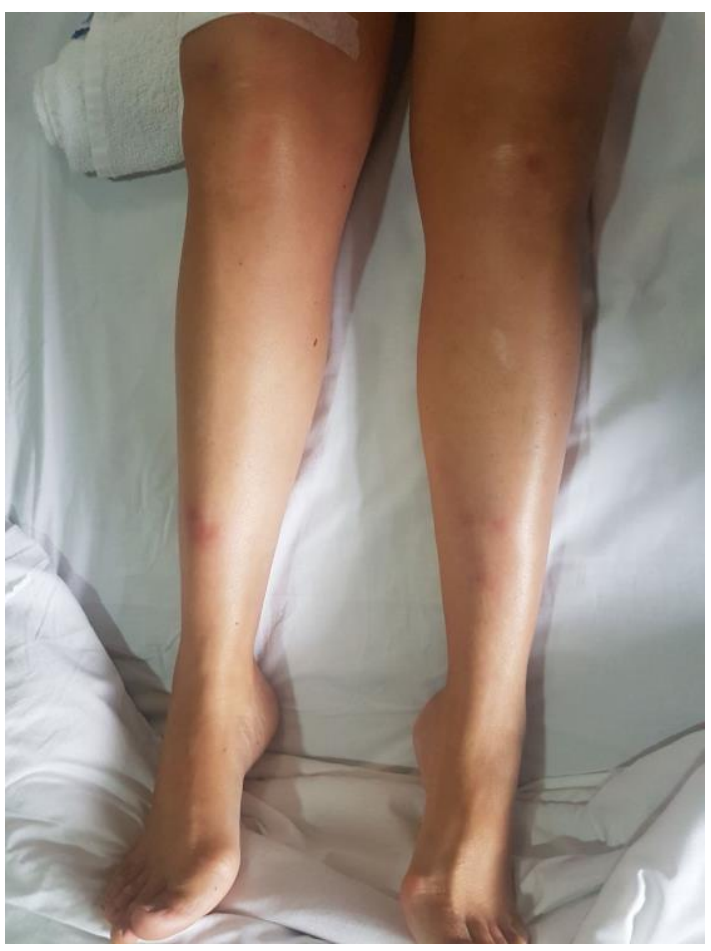

Figura n'2.Eritema Nodosopretibial bilateral.

Manifiesta que dos semanas previas a la consulta presentó odinofagiaseundaria a úlceras orales, las cuales eran recurrentes desde la adolescencia, y candidiasis vulvovaginal por la cual se automedico con antifúngicos.

$\mathrm{Al}$ examen físico se encuentra febril y se objetivan úlceras, una en mucosa yugal y otra de en mucosa vaginal (Ver figura $n^{\circ} 3$ ). Se constata eritema nodoso bilateral en ambos miembros inferiores, acompañando a artritis de rodilla derecha con signo de la tecla positivo.

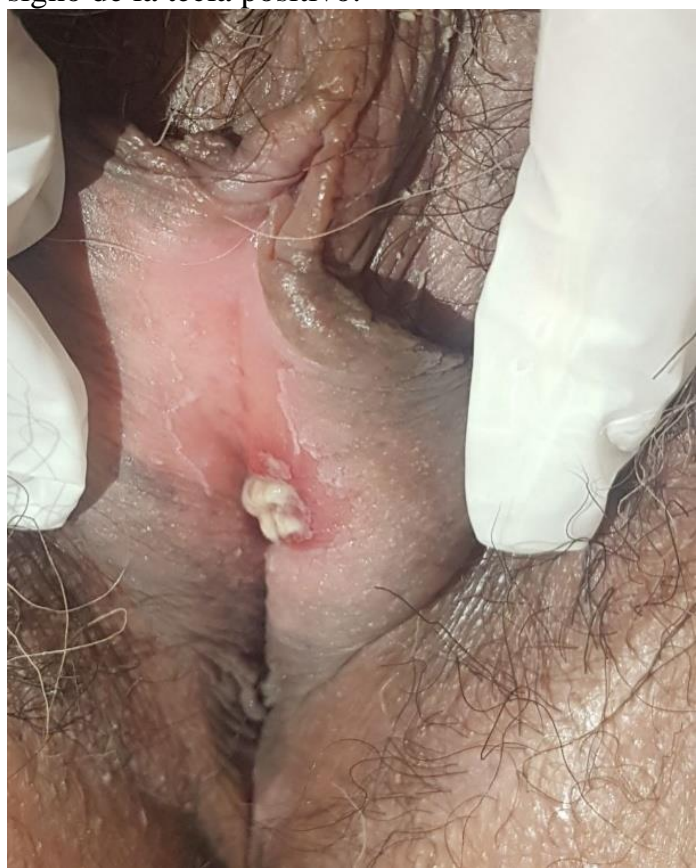

Figura n⿳3. úlcera a nivel vulvovaginal
Se realiza hemograma y bioquímica sanguínea con los siguientes resultados: leucocitos 14300 (conneutrofilia), eritrosedimentación(VSG) 47, proteína c reactiva (PCR) 150. También se obtiene muestra de líquido sinovial arrojando como resultado: líquido turbio, leucocitos 6500 (80\% polimorfonucleares), proteínas $2.66 \mathrm{~g} \%$, glucosa $0.47 \mathrm{~g} / \mathrm{L}$. Se realiza tratamiento empírico con cefazolina y gentamicina. Se solicita serología para sífilis, virus de inmunodeficiencia adquirida(VIH), virus de hepatitis B (VHB), virus de hepatitis C (VHC) anticuerpo antinuclear (ANA), anticuerpo anticitoplasma de neutrófilos (p ANCA cANCA) todos negativos. Presenta prueba de patergia negativa, pero si tiene reacción positiva en dos sitios de venopunción para extracción sanguínea. Se obtiene resultado de biopsia de lesiones en miembros inferiores compatible con paniculitis septolobular, y de mucosa yugal donde se encontró proceso inflamatorio neutrofílico con vasculitis, compatible con síndrome de behçet. Se estudia HLA locus B, donde se observa el alelo B 51. En este caso al reunir la presentación clínica, la muestra anatomopatológica y los hallazgos de laboratorios, arribamos al diagnóstico de enfermedad de Behçet.

Se comienza tratamiento con meprednisona ocho $\mathrm{mg}$ / día, con lo cual se objetiva mejoría clínica y de patrones inflamatorios en laboratorio.

La enfermedad de Behçet es una entidad muy infrecuente en nuestro país, donde no contamos con registros en la bibliografía acerca de la prevalencia. La frecuencia de la misma es mayor en Turquía donde se presentan aproximadamente 80-370 casos por 100.000, habitualmente en varones de 30 años ${ }^{1}$. Se desconoce la etiología, pero se cree que la combinación, un mismo paciente, de factores genéticos y medioambientales juegan un rol importante. Se describe asociación con el HLAB57 en países occidentales, mientras que en orientales el HLAB51 se relaciona con formas más severas de afectación ocular ${ }^{1}$.

La presentación clínica más frecuente es el compromiso mucocutáneo, con úlceras bucales recurrentes dolorosas (97\%) y genitales (60-90\%). Con respecto a las mismas, pueden objetivarse como lesiones herpetiformes, como ocurrió en nuestra paciente al encontrar la lesión genital, pero la misma fue estudiada con inmunofluorescencia para virus herpes uno y dos, resultando negativa. Dentro del compromiso cutáneo encontramos nódulos subcutáneos en forma de eritema nodoso, funiculitis, pioderma gangrenoso y tromboflebitis migratoria superficial. Se encuentran descrito en la literatura, manifestaciones oculares $(70 \%)$, gastrointestinales $(25 \%)$, en sistema nervioso, musculoesqueléticas y vasculares $(35 \%$, trombosis

Revista Methodo: Investigación Aplicada a las Ciencias Biológicas. Universidad Católica de Córdoba. Jacinto Ríos 571 Bo Gral. Paz. X5004FXS. Córdoba. Argentina. Tel.: (54) 3514517299 / Correo: methodo@ucc.edu.ar / Web: methodo.ucc.edu.ar | CASO CLINICO Methodo 2018;3(4):131-138 
venosa y arterial)1. Nuestra paciente fue estudiada con un fondo de ojo para descartar compromiso ocular, el cual fue normal. Con respecto a las manifestaciones articulares se describen artralgias y artritis (mono, oligo o poliartritis) de similares características a las encontradas en otras conectivopatías.

La enfermedad no presenta un cuadro clínico ni hallazgos de laboratorio patognomónicos, por lo que el diagnóstico se realiza evaluando los criterios del Grupo Internacional de Estudio de EB 1990 (Tabla 2), y excluyendo las entidades más relevantes a tener cuenta en la disquisición.

Ejemplo de éstas son la enfermedad inflamatoria intestinal como la enfermedad de Crohn, úlceras genitales secundarias a infecciones de transmisión sexual, lupus o vasculitis asociada a $\mathrm{ANCA}^{2}$. Cuando se presenta con eritema nodoso es importante descartar las etiologías más frecuentes del mismo como sarcoidosis e infecciones, entre otras (tabla 3).

El tratamiento debe tener como objetivo disminuir los síntomas de dolor, prevenir las recurrencias, y reducir la morbimortalidad. Se utilizan medidas no farmacológicas y farmacológicas. Entre las últimas encontramos la colchicina, esteroides, drogas modificadoras de la enfermedad (metotrexato, azatioprina) y anti -TNF. La Talidomida es de uso excepcional $^{3}$. El principio del tratamiento es encontrar el esquema más efectivo y menos tóxico posible. (tabla 4-5)

\section{Bibliografía}

1. Jagdish R, Nair A, Moots RB. Behcet'sdisease.

$\mathrm{CME}$ RHEUMATOLOGY.

2. Clinical Medicine 2017 Vol 17 No 1: 71-7.

3. Unizony S, Kim N, Hoang MP, Case: A 25Year-Old Manwith Oral Ulcers, Rash, and Odynophagia. N Engl J Med 2015; 864-872

4. Turrión N., Movasat H., Álvarez-Mon S. Vasculitis. Arteritis de grandes arterias. Enfermedad de Behçet. Enfermedad de Kawasaki. Medicine. 2013;2029-3.

\section{Palabras claves}

ENFERMEDAD DE BEHÇET; ERITEMA

NODOSO; ARTRITIS; FIEBRE

\section{Keywords}

\author{
BEHÇET'S DISEASE; ERYTHEMA \\ NODOSUM; ARTHRITIS; FEVER.
}

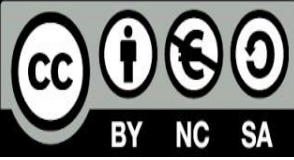




\section{Anexo tablas}

Tabla 1-Definiciones para vasculitis adoptadas por la Conferencia Internacional de Consenso de Chapel Hill 2012 sobre la Nomenclatura de Vasculitis (CHCC2012)

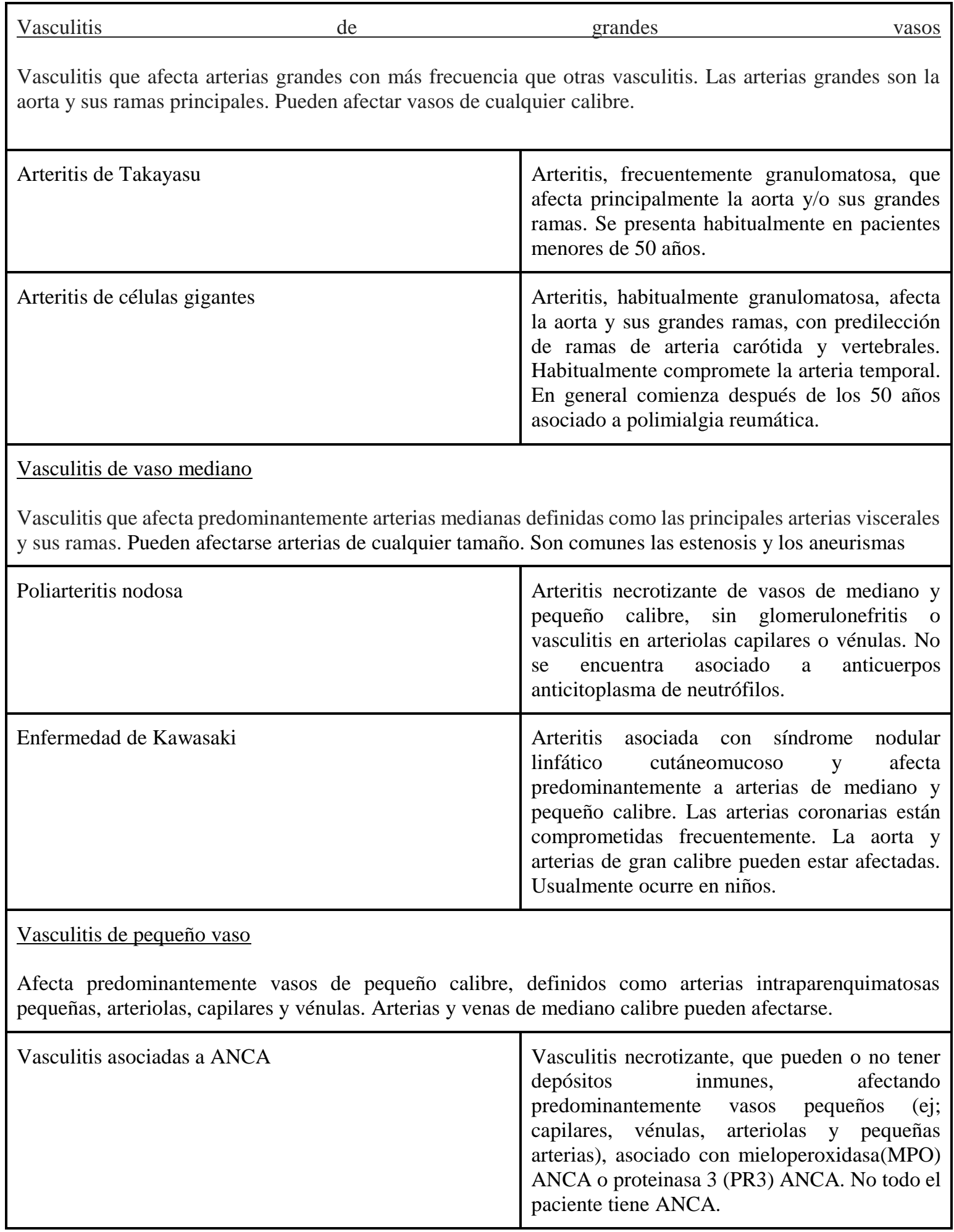




\begin{tabular}{|c|c|}
\hline Poliangeítis microscópica & $\begin{array}{l}\text { Vasculitis necrotizante, que pueden o no tener } \\
\text { depósitos inmunes, afectando } \\
\text { predominantemente vasos pequeños (ej.; } \\
\text { capilares, vénulas, arteriolas y pequeñas } \\
\text { arterias). Glomerulonefritis necrotizante y } \\
\text { capilaritis pulmonar son comunes. No existe } \\
\text { inflamación granulomatosa. }\end{array}$ \\
\hline Granulomatosis con poliangeítis (Wegener) (GPA) & $\begin{array}{l}\text { Inflamación necrotizante granulomatosa que } \\
\text { usualmente involucra el tracto respiratorio } \\
\text { superior e inferior, y afecta predominantemente } \\
\text { vasos de pequeño y mediano calibre. La } \\
\text { glomerulonefritis necrotizante es común. }\end{array}$ \\
\hline $\begin{array}{l}\text { Granulomatosis eosinofílica con poliangeítis (Churg } \\
\text { Strauss) (EGPA) }\end{array}$ & $\begin{array}{l}\text { Inflamación necrotizante granulomatosa rica en } \\
\text { eosinófilos que compromete tracto respiratorio } \\
\text { inferior. Vasculitis necrotizante que afecta } \\
\text { predominantemente vasos de pequeño y } \\
\text { mediano calibre., y se asocia con asma y } \\
\text { eosinofilia. Los ANCA son más frecuentes } \\
\text { cuando la glomerulonefritis está presente. }\end{array}$ \\
\hline Vasculitis con complejos inmunes & $\begin{array}{l}\text { Vasculitis con deposito moderado o severo en la } \\
\text { pared de los vasos de inmunoglobulinas y/o } \\
\text { complemento, predominantemente afectando } \\
\text { vasos de pequeño calibre. La glomerulonefritis } \\
\text { es }\end{array}$ \\
\hline $\begin{array}{l}\text { Enfermedad por anticuerpos antimembrana basal } \\
\text { glomerular }\end{array}$ & $\begin{array}{l}\text { Vasculitis que afecta capilares glomerulares o } \\
\text { pulmonares, o ambos, con depósito de } \\
\text { anticuerpos anti-GBM. El compromiso } \\
\text { pulmonar causa hemorragias pulmonares y la } \\
\text { afectación renal ocasiona glomerulonefritis con } \\
\text { necrosis y semilunas. }\end{array}$ \\
\hline Vasculitis crioglobulinémica & $\begin{array}{l}\text { Vasculitis con depósito de crioglobulinas } \\
\text { afectando pequeños vasos asociado con } \\
\text { aumento de crioglobulinas en sangre. Piel, } \\
\text { glomérulos y nervios periféricos son } \\
\text { frecuentemente afectados. }\end{array}$ \\
\hline Vasculitis IgA (SchonleinHenoch) & $\begin{array}{l}\text { Vasculitis, con depósito predominante de IgA1, } \\
\text { afectando pequeños vasos. Comúnmente } \\
\text { involucra la piel y el tracto gastrointestinal, y } \\
\text { frecuentemente ocasiona artritis. La } \\
\text { glomerulonefritis puede ser indistinguible de la } \\
\text { nefropatía por IgA. }\end{array}$ \\
\hline $\begin{array}{l}\text { Vasculitis hipocomplementémica urticarial (anti-C1q } \\
\text { vasculitis) }\end{array}$ & $\begin{array}{l}\text { Vasculitis acompañada de urticaria e } \\
\text { hipocomplementemia afectando vasos } \\
\text { pequeños. y asociada con anticuerpos anti -C1q. } \\
\text { Se presenta con glomerulonefritis, artritis, } \\
\text { enfermedad pulmonar obstructiva e inflamación } \\
\text { ocular. }\end{array}$ \\
\hline \multicolumn{2}{|l|}{ Vasculitis de vaso variable } \\
\hline
\end{tabular}


Vasculitis en la cual no se afecta un tipo ni tamaño especial de vaso.

\begin{tabular}{|l|l|}
\hline Enfermedad de Behçet & $\begin{array}{l}\text { Vasculitis que ocurren en pacientes con } \\
\text { enfermedad de Behçet pueden afectar arterias o } \\
\text { venas. Esta enfermedad se caracteriza por úlcera } \\
\text { orales y/o genitales recurrentes, acompañada de } \\
\text { afectación cutánea, ocular, articular, } \\
\text { gastrointestinal y /o de sistema nervioso central. } \\
\text { Puede ocurrir vasculitis de vaso pequeño, } \\
\text { tromboangeítis, trombosis, arteritis y y } \\
\text { aneurismas arteriales. }\end{array}$ \\
\hline Síndrome de Cogan & $\begin{array}{l}\text { Vasculitis que ocurre en pacientes con } \\
\text { Síndrome de Cogan. Éste se caracteriza por } \\
\text { lesiones oculares inflamatorias, que incluyen } \\
\text { queratitis intersticial, uveítis, y epiescleritis, y } \\
\text { enfermedad del oído interno, produciendo } \\
\text { pérdida de la audición neurosensitiva y } \\
\text { disfunción vestibular. Las manifestaciones por } \\
\text { vasculitis pueden incluir arteritis, aortitis y } \\
\text { aneurismas aórticos, así como también } \\
\text { valvulitis mitral. }\end{array}$
\end{tabular}

Vasculitis de un sólo órgano

Vasculitis en arterias o venas de cualquier tamaño en un sólo órgano que no tiene características que indiquen que es la expresión limitada de una vasculitis sistémica. El compromiso del órgano y el tipo de vaso deben incluirse en el nombre (ej., vasculitis cutánea de pequeño vaso, arteritis testicular, vasculitis del sistema nervioso central). Puede ser de distribución unifocal o multifocal (difusa) dentro de un órgano. Algunos pacientes son diagnosticados de vasculitis de un sólo órgano pudiendo desarrollar más adelante manifestaciones adicionales, redefiniendo el cuadro como una vasculitis sistémica ( ej.; arteritis cutánea que se convierte en poliarteritis nodosa)

$\underline{\text { Vasculitis asociada con enfermedad sistémica }}$

Vasculitis que es asociada y a la vez puede ser secundaria a una enfermedad sistémica. El nombre (diagnóstico) debe tener el prefijo específico de la enfermedad sistémica. (ej.; vasculitis reumatoidea, vasculitis lúpica).

Vasculitis asociada con etiología probable

Vasculitis que se asocia con una etiología probable específica. El nombre (diagnóstico) debe tener el término haciendo alusión a la asociación específica. ( ej.; poliangeítis microscópica asociada a hidralazina, vasculitis asociada a virus de hepatitis $\mathrm{B}$, vasculitis crioglobulinémica asociada a virus hepatitis C) 
Tabla 2-Criterios diagnósticos de enfermedad de Behcet

\begin{tabular}{|c|c|}
\hline Criterios & Signos \\
\hline Ulceras Orales a repetición & $\begin{array}{l}\text { Aftas menores, aftas mayores o ulceraciones } \\
\text { herpetiformes observadas por médico o paciente, las } \\
\text { cuales recurren por lo menos } 3 \text { veces en un periodo de } \\
12 \text { meses. }\end{array}$ \\
\hline \multicolumn{2}{|l|}{ Más 2 de los siguientes: } \\
\hline Ulcera Genital Recurrente & Ulceras o aftas observadas por médico o paciente \\
\hline Lesión ocular & $\begin{array}{l}\text { Uveítis anterior, uveítis posterior observadas en } \\
\text { lámpara de hendidura observadas por oftalmólogo }\end{array}$ \\
\hline Lesión en piel & $\begin{array}{l}\text { Eritema Nodoso observado por médico o paciente, } \\
\text { pseudofoliculitis o lesiones papulopustulosas, o } \\
\text { nódulos acneíformes observados por médicos. }\end{array}$ \\
\hline Test de Patergia positivo & Leído por médicos a las 24-48hs. \\
\hline
\end{tabular}

Tomado y modificado de Jagdish R, Nair A,Moots RB. Behcet's disease.CME

RHEUMATOLOGY. Clinical Medicine 2017 vol 17 No 1:71-7

Tabla 3 -Drogas Modificadoras de Enfermedad (Dmards) usadas en Enfermedad de Behcet (Parte I)

\begin{tabular}{|c|c|}
\hline Drogas por Vía Oral & Dosis \\
\hline Azatioprina & $2-3 \mathrm{mg} / \mathrm{kg} / \mathrm{dia}$ \\
\hline MycofenolatoMofetil & $2-3 \mathrm{~g} / \mathrm{dia}$ \\
\hline Methotrexate & $20-25 \mathrm{mg} / \mathrm{dia}$ \\
\hline Tacrolimus & 4-8 mg/day (depende de niveles en plasma) \\
\hline Ciclosporina & $2.5 \mathrm{mg} / \mathrm{kg} / \mathrm{dia}$ \\
\hline Sulfasalazina & $2-3 \mathrm{~g} / \mathrm{dia}$ \\
\hline Dapsona & $2-3 \mathrm{mg} / \mathrm{kg} / \mathrm{dia}$ \\
\hline Talidomida (uso excepcional) & $50-300 \mathrm{mg} / \mathrm{dia}$ \\
\hline Colchicina & $0.5-2 \mathrm{mg} / \mathrm{dia}$ \\
\hline Prednisolona & Dosis variable \\
\hline \multicolumn{2}{|l|}{ Drogas por via parenteral } \\
\hline Ciclofosfamida & $15 \mathrm{mg} / \mathrm{kg}$ dosis para vasculitis \\
\hline \multicolumn{2}{|l|}{ Inhibidores anti TNF } \\
\hline Infliximab & $5 \mathrm{mg} / \mathrm{kg}$ \\
\hline Adalimumab & $40 \mathrm{mg} 2$ veces por semana \\
\hline Etanercept & $50 \mathrm{mg}$ por semana \\
\hline Certolizumab & $400 \mathrm{mg} \mathrm{0,2}$ y 4 semanas y luego 1 por semana \\
\hline
\end{tabular}


Gutiérrez Magaldi I, Bulacio E, Camporro F, Bertorello MN, Furrer S, Bressan V, Lucero P. Úlceras orales a repetición y eritema nodoso: pensar en Enfermedad de Behçet

Tabla 3 -Drogas Modificadoras de Enfermedad (Dmards) usadas en Enfermedad de Behcet (Parte II)

\begin{tabular}{|l|l|}
\hline Rituximab & $1 \mathrm{~g} 0$ y 2 semanas \\
\hline Interferon Alfa & $\begin{array}{l}\text { Varios regimenes para ROFERON Alfa e Interferonpegilado Alfa 2 } \\
\mathrm{b}\end{array}$ \\
\hline Alemtuzumab & $3 \mathrm{mg}$ (día 1), $10 \mathrm{mg}$ (día 3), $30 \mathrm{mg}$ (día 5, 8, y 12) \\
\hline
\end{tabular}

Tabla 4-Nuevos medicamentos en el horizonte

Apremilast-inhibidor de fosfodiesterasa 4

Anakinra-Antagoniosta receptor interleukina 1

Canakinumab-Inmunoglobulina G1 inhibidor de IL-1 B

Tacilizumab-Inhibidor de IL6

Ustekinumab-IL 12/23

\section{(c) (1)(2) \\ BY NC SA}

